\title{
Mental health promotion and socio-economic disadvantage: lessons from substance abuse, violence and crime prevention and child health
}

\author{
J. W. Toumbourou, S. A. Hemphill, J. Tresidder, C. Humphreys, J. Edwards and D. Murray
}

\author{
Introduction \\ In the past 40 years there has been increasing economic and \\ policy intervention to reduce unemployment and poverty and \\ to decrease the impact of social and economic disadvantage. \\ At the same time, there has been increasing pressure for \\ outcomes from social policy programs to be evaluated. As a \\ result, particularly in the United States (US), large-scale studies \\ have attempted to measure the impact of intervention activities \\ on outcomes for individuals and groups. Social policy and \\ interventions that specifically address health and social problems, \\ including youth alcohol and drug (substance) abuse, mental
}

\begin{abstract}
illness and crime and violence, have been evaluated. Such prevention efforts and associated research have increased what is known about developmental behaviour and associated life pathways. The association between factors such as SES and health and psychological outcomes have also been explored.

While many of the studies included in the present article were conducted in the US, they may have application in Australia. Although the context is culturally different in Australia, many of the same associations between risk factors and adverse outcomes have been noted in epidemiological work undertaken here. There has been less investment in high-quality evaluation studies
\end{abstract}

\section{Abstract}

Issue addressed: Mental health promotion aimed at populations with low socio-economic status (SES) may benefit by investigating prevention strategies that effectively address related child and adolescent problems.

Methods: Evidence from a number of literature reviews and program evaluations was synthesised. First, the impact of SES on development from childhood to adulthood is considered in light of research on substance abuse, violence, crime, and child development problems. Second, evaluations of interventions are reviewed to identify those that have shown outcomes in research studies (efficacy) or in real-world settings (effectiveness) in reducing developmental problems associated with low SES. Low SES is measured in different ways including low levels of education and/or income or definitions that combine several variables into a new indicator of low SES.

Results: Factors associated with low SES are also associated to varying extent with the development of violence and crime, substance abuse and child health problems. Interventions that address underlying determinants of low SES show strong efficacy in decreasing adolescent crime and violence and effectiveness in improving child health outcomes. Although there is limited efficacy evidence that substance abuse prevention can be effectively addressed by targeting low SES, programs designed to improve educational pathways show some efficacy in reducing aspects of adolescent substance use.

Conclusion: Mental health promotion strategies can draw on the approaches outlined here that are associated with the prevention of child and adolescent problems within low SES communities. Alternatively, such interventions could be supported in mental health promotion policy as they may assist in preventing related problems that undermine mental health.

Key words: Child development, socio-economic disadvantage, prevention, alcohol abuse, substance abuse, violence, crime, child health. 
of prevention programs in Australia and Europe. This article presents a synthesis of prevention findings gleaned from literature reviews and evaluation studies that could inform policy and program development in Australia and could be evaluated to test their effectiveness in our cultural context.

The aim of this article is to:

(a) Bring together knowledge relevant to the link between socioeconomic status (SES) and a range of problems that influence mental health (crime and violence, harmful substance use and child health).

(b) Summarise the evidence to highlight the potential contribution of specific intervention programs that seek to reduce problems associated with and affecting the mental health of individuals and groups experiencing socioeconomic disadvantage.

\section{Method}

Recently completed systematic literature reviews were identified. ${ }^{1-8}$ Electronic search strategies were also used to locate additional review and empirical papers published in recent years. Review papers were included only if they met quality standards for systematic selection and methodological evaluation such as explicit criteria for inclusion, appraisal and synthesis ${ }^{9,10}$ and the evaluation of underlying processes. ${ }^{11}$ Key evidence is also presented in this article from well-conducted and influential empirical studies. Implications for research and practice from such studies are noted.

As this article draws together a broad range of research, only major conclusions about the influence of socio-economic disadvantage on health and social problems are discussed. Evidence supporting SES as a causal contribution is only included if both longitudinal analyses and tests of causal theories indicated such a conclusion was warranted.

Following this, conclusions about intervention effects are made. Intervention efficacy is reported where there was overall positive evidence of impact from well-controlled outcome evaluations. This article regards interventions as effective where outcomes have been maintained when efficacious interventions were delivered in real-world service delivery contexts. ${ }^{12}$

Socio-economic disadvantage was defined on the basis of three indicators: low education; low income; and low cumulative status across multiple indicators of education, income, occupation, housing, and welfare. In this article, low SES is defined comparative to a majority with higher status and does not necessarily refer to insufficient resources to fulfil basic needs.

\section{Results}

Table 1 documents the main results from this review. It summarises the evidence that health and social problems (column 1) are influenced by SES (column 2). The table also summaries the evidence that indicates these problems can be prevented through interventions that address factors associated with low SES (column 3). The sections that follow elaborate on the ratings presented in Table 1.

\section{The influence of low SES on violence and crime}

Violence can undermine childhood environments, particularly, although not exclusively, through domestic violence, which is discussed in later sections examining child health and abuse. Low SES is linked to higher rates of participation in youth violence and crime. However, SES is only one among numerous factors that influence development and is therefore one of the multiple targets in the prevention of youth violence and crime. Considerable research has addressed the development of violence and offending in adolescence and this work has consistently noted the influence of low SES. In addition, theories have been developed and tested to specifically describe and explain the links between being a lower (working) class male and engaging in delinquency (e.g. the theories of Albert Cohen, Richard Cloward and Lloyd Ohlin, and Walter Miller ${ }^{13}$ ). In both developed and developing countries, the rate of growth of gross domestic product (GDP) is associated with lower homicide rates. ${ }^{14}$ However, this effect is often counteracted by rising levels of income inequality. ${ }^{14}$ This means that the aggregate benefit of economic advancement on the reduction of crime and violence will be diluted when advancement is unequal (a similar effect is noted below for child health).

Evidence from US trend-series analyses demonstrated that improvements in State unemployment rates in the 1990s reduced property crimes but had less impact on violent crimes. ${ }^{15}$ Some reviewers have failed to find effects of 'social class' on

Table 1: Evidence that health and social problems are influenced by socio-economic status (SES) and can be prevented through SES interventions.

\begin{tabular}{|c|c|c|}
\hline Health and social problem & Evidence for influence of low SES & $\begin{array}{l}\text { Evidence problem can be prevented } \\
\text { through SES intervention }\end{array}$ \\
\hline Violence and crime & One among a number of identified influences & Strong efficacy evidence \\
\hline Substance abuse & Small influence at population level & Limited efficacy evidence \\
\hline Child health, abuse and neglect & Important component among multi-determined influences & Effectiveness evidence \\
\hline
\end{tabular}


youth violence and crime. ${ }^{16}$ However, generally researchers ${ }^{17-19}$ have found that being raised in conditions of low SES is associated with higher engagement in youth violence and crime, particularly when the measures of SES include poverty and unemployment. ${ }^{13}$ In the Australian context, researchers ${ }^{20}$ have presented evidence demonstrating that the increased adolescent delinquency predicted by low SES may be mediated by poor parenting. The age at which children and adolescents are exposed to low SES also has an impact on the association with youth violence and crime. One review ${ }^{21}$ found that SES was a predictor of youth violence and crime when it was measured at ages 6-11 years but not at ages 12-14 years.

\section{Influence of low SES on tobacco, alcohol and illicit drug-related harm}

The overall population prevalence of tobacco and alcohol use does not appear to be predictably influenced by socio-economic trends. ${ }^{4}$ However, poverty often increases the harm for a given level of alcohol and other drug (substance) use. ${ }^{22}$ In the Australian context, population rates of tobacco use have been dropping for several decades in response to effective public health strategies. A number of studies have noted that the trend to quit tobacco use or avoid uptake has been resisted in specific populations, including low SES. ${ }^{23,24}$ Lower SES populations show a higher prevalence of practices that hold the potential to harm children, including tobacco and alcohol use in pregnancy and exposure of children to environmental tobacco smoke. ${ }^{4}$ Low education, low status and lack of money have all been implicated as factors that can undermine family contributions to healthy child development. Child development problems in turn lead to experiences of developmental distress that have been implicated as motives for the most severe forms of harmful alcohol and drug abuse. ${ }^{7}$ Although the research is not in complete agreement, the available evidence from large, epidemiological, longitudinal studies suggests that lower levels of employment or reductions in cumulative SES predict slight increases in population-level heavy alcohol use and alcoholrelated harms. ${ }^{25-27}$ These trends appear better explained by the effects of economic stress ${ }^{28}$ rather than the increased availability of leisure ${ }^{26,29}$ and may not be apparent when the measure is 'social class' (e.g. low work responsibility) rather than disadvantage (e.g. low income and education). ${ }^{30}$

\section{Influence of low SES on child health, abuse and neglect}

Available research presents a consistent picture suggesting socioeconomic disadvantage adversely influences child health, child abuse and neglect. However, the advantage of higher SES for child health may plateau at higher levels of SES. At a global level, the economic progress of developing nations is closely linked to reductions in child mortality. ${ }^{31} \mathrm{~A}$ paradox is evident in many developed countries, including Australia, such that the recent overall increase in material conditions has not necessarily increased health and well-being for children. ${ }^{32}$ Two explanations have been proposed for this plateau effect. One is that the general increase in material well-being has been unequally distributed. The second is that while infectious diseases and mortality rates have been very significantly reduced, there has been a more general increase in other major health problems for children including obesity, asthma, and childhood diabetes. Parental problems also threaten the health and well-being of children including child abuse, substance abuse and mental illness. These problems fall disproportionately on children living in low SES families. ${ }^{5}$ A very clear and disturbing health gradient is evident in Australia with increasing child health risks directly proportionate to not only increasing disadvantage, but also increased remoteness. The latter is most notably associated with an increase in the proportion of Indigenous children in remote areas of Australia. ${ }^{33}$ Indigenous children have higher rates of all child health problems including infant mortality, which is three times the rate of the non-Indigenous population. ${ }^{32,33}$

The relationship between increasing child abuse and neglect and socio-economic disadvantage is evidenced both in Australian national ${ }^{32}$ and international studies. ${ }^{34}$ These studies show correlates with low birth weight, child behaviour problems, teenage pregnancy, drug and alcohol use and low literacy. Studies often show strong connections between the health and wellbeing of women and those of their children. ${ }^{35}$ In particular, the impact of family violence, which is the most significant risk factor for the health of women under $45,{ }^{36}$ is also a high risk factor for both the mental and physical well-being of children. ${ }^{37}$ Prevalence data available from the United Kingdom (UK) is indicative of a strong correlation between family violence and socio-economic disadvantage for women and children. ${ }^{38,39}$

\section{Interventions that prevent violence and crime by addressing SES determinants: strong efficacy evidence}

Efficacy evidence from prevention studies shows that programs that address determinants of SES also succeed in reducing developmental pathways to violence and crime. A notable US study examined the effect on youth violence of physically relocating families out of areas that had a high concentration of poverty. 'Moving to Opportunity' in Maryland divided families from high poverty areas into three groups: a) families who received subsidies, counselling and other assistance to move to communities with lower levels of poverty; b) families who received subsidies only; and c) families who received no special assistance. Decreases in adolescent violent behaviour were found for families who were supported to move to neighbourhoods with low poverty levels (Ludwig et al. ${ }^{14}$ ). These promising findings suggest that further research may be warranted to identify how economic and structural factors could be modified to reduce their contribution to youth violence. 
Economic measures that improve employment appear to reduce property crime. ${ }^{15} \mathrm{~A}$ number of prevention approaches have been developed and tested to prevent youth violence and crime in socially disadvantaged communities. There is efficacy evidence from systematic literature reviews ${ }^{1-3}$ suggesting that improving educational pathways may reduce crime. Not surprisingly, given the breadth of risk factors across individual, family, peer, school and community levels of influence that have been identified for youth violence and crime, serious prevention attempts target multiple risk factors, of which low SES is one.

\section{Interventions that prevent tobacco, alcohol and drug-related harm by addressing SES determinants: limited efficacy evidence}

Despite epidemiological analyses showing that economic participation and employment contribute to population reductions in heavy alcohol use and tobacco use (see above), current evidence does not support socio-economic intervention as a sufficient strategy for reducing population rates of substance abuse. ${ }^{4}$ Although enhancing SES may not reduce population levels of substance abuse, it may be feasible to reduce some contribution of low SES to aspects of substance abuse. ${ }^{23,28}$

One important strategy for reducing population levels of alcohol and tobacco use is to increase price relative to available income. This strategy works universally but may have a greater impact on populations with low income. ${ }^{4}$ However, in the absence of support and treatment, there is potential for price increases to diminish vulnerable family budgets. There is consistent evidence that specific programs designed to improve children's educational outcomes (an important factor that can increase SES) also contribute to preventing the development of substance use in adolescence. A number of interventions that have been designed to improve childhood education outcomes have demonstrated reductions in adolescent alcohol and drug use. ${ }^{40}$

Efficacy evidence also supports the potential to reduce childhood pathways to harmful substance use by targeting specific child development assistance to low SES families. ${ }^{4,23}$ Services involving highly trained professionals visiting the homes of disadvantaged and vulnerable mothers have been experimentally tested within small samples. When followed-up into adolescence, the children of mothers supported by this intervention showed lower rates of alcohol and drug use, better mental health and upward mobility in their employment and income status. ${ }^{41}$ Interventions have also been developed to improve parenting skills among disadvantaged and drug-using parents. Small efficacy trials have revealed that parents exposed to these interventions show improvements in parenting skills and reductions in alcohol and drug use. It remains unclear whether these interventions improve child outcomes. ${ }^{42}$

\section{Interventions that prevent child mortality, abuse and neglect by addressing SES determinants: effectiveness evidence}

There is effectiveness evidence that interventions designed to enhance socio-economic conditions can improve child health. These programs typically do not pursue a simple socio-economic focus but tend to be multi-faceted. ${ }^{34,43}$ This reflects understandings of socio-economic disadvantage and the relationship with children's health and well-being that go beyond income as the only measure of disadvantage, but look at multiple dimensions of material well-being, health and safety, educational well-being, family and peer relationships, behaviour and risks, and subjective well-being. ${ }^{35}$ For many years, rates of child mortality have been falling in response to international programs that incorporate economic assistance as an integral component of measures to address child health. The Campaign for Child Survival is a noteworthy example of an integrated United Nations program that has a sound track record for effectiveness. ${ }^{31}$ Closer to home, a particularly powerful example of an intervention that has evidence for effectiveness in the Newcastle region is the Hunter Community Renewal Program, which incorporated economic assistance within a multi-layered program. ${ }^{44}$ Assessment of the impact of this program has included data on low birthweight within the locality, which has shifted in a fouryear period from a 15th ranked position to an improved 462nd rank by NSW postcode. Similarly, rates of maltreatment shifted from a rank of sixth to a rank of 454th over the same period.

\section{Examples of promising Australian programs}

In the sections that follow we point to examples of promising Australian programs where evidence has been drawn from across disciplines to develop effective practices. These programs are reported as they either address SES determinants or target low SES groups and have incorporated evaluation.

\section{Pathways to Prevention: early years crime prevention}

Inter-generational disadvantage is often perpetuated in low SES communities due to a loss of social capital relevant to healthy child development. To address this issue, early years intervention programs have been developed. A recent Australian example is Pathways to Prevention, ${ }^{45}$ a universal, early intervention, developmental prevention project. Its aim is to reduce the intergenerational continuity of disadvantage by organising social resources to support children, families and their communities before problems emerge (not necessarily early in life). The project focused on the transition to primary school in one of the most disadvantaged urban areas in Queensland. ${ }^{45}$ Using a community development framework, it combined child-focused programs delivered universally through State preschools (the Preschool Intervention Program) with individual services for families (the Family Independence Program). 
A quasi-experimental design was used to evaluate the impact of the program. Data were collected at baseline, postintervention and in the year following the intervention when children were in their first year at primary school $(n=647$ children). In brief, intervention effects were reported more strongly for boys in the areas of reduced teacher-reported behaviour problems and increased both teacher-reported prosocial behaviour and readiness for school. For both boys and girls, language skills improved and overall behavioural problems were reduced. Further trials and development of this promising intervention are continuing.

\section{Improving primary school environments}

The success of a number of US trials has encouraged efforts to conduct similar primary school improvement programs in Australia. Two notable primary school improvement programs are KidsMatter and the RAMP program. KidsMatter is a primary school mental health promotion, prevention and early intervention initiative developed in collaboration with the Federal Government (http://www.apapdc.edu.au/kidsmatter/). The program includes: activities to improve school climate; social and emotional competence curriculum; family involvement; and early intervention components. It is being evaluated in a large waiting-list control trial.

RAMP (Risk Assessment and Management Process) is a program that encourages a partnership between schools and mental health agencies. Process evaluation suggested the intervention is feasible and encourages school staff to monitor evidencebased factors that influence student mental health and deliver tailored interventions to targeted students. ${ }^{46}$ Findings relevant to effects on students are not yet available for either of these primary school improvement programs.

A notable US example of a comprehensive and effective primary school approach to youth violence, crime and substance abuse prevention is the Seattle Social Development Project (SSDP). ${ }^{47}$ This longitudinal intervention was delivered to one group from the first year of primary school and to another from Grade 6 and targeted schools in high-crime neighbourhoods. The program provided training to teachers (proactive classroom management, interactive teaching and co-operative learning techniques), students (social skills training), and parents (effective parenting and ways to support their children's educational success). A control group did not receive any special intervention. Multiple informants and multi-method measurement was used to assess a comprehensive list of risk and protective factors and outcome measures. ${ }^{48}$

Evidence from this intervention suggests that it has successfully reduced a number of factors that underlie the intergenerational transfer of poverty. Relative to the control students, those exposed to the intervention have shown increased levels of school bonding, reductions in school failure, drug abuse and delinquency and reductions in early pregnancy and sexual risktaking behaviour. ${ }^{49}$ At the end of high school, heavy drinking was reported by fewer of the students who had received the full intervention (15.4\%) relative to those in the control schools (25.6\%). ${ }^{50}$ Positive effects in improving educational pathways have been most pronounced for children from low SES backgrounds. ${ }^{51}$

\section{Improving secondary school environments}

Work completed at the Centre for Adolescent Health has provided several potential directions for improving educational environments in disadvantaged secondary schools. The Gatehouse Project (www.gatehouseproject.com) is a Victorian, school-based, primary prevention program aiming to improve the emotional well-being of secondary students by offering a framework for building the capacity of school communities. Resources include student emotional competence curricula and professional training for teachers. A cluster randomised trial in 12 intervention and 14 comparison schools has been used to evaluate the project. The evaluation found a 3-5\% reduction in substance use for early secondary school students exposed to the intervention when followed up over 2-3 years. ${ }^{52,53}$

A further strategy that has been developed to improve secondary school environments and reduce adolescent substance misuse involves the encouragement of parent education and family involvement at school. An Australian trial achieved reductions in student initiation to substance use within a three-month trial that compared 14 intervention schools with 14 comparison schools. The intervention involved offering parent education groups to all parents in early secondary school. ${ }^{54}$ This promising trial led to the development of Resilient Families, a program providing information and support to both students and their parents within disadvantaged school communities. ${ }^{46}$ The project has been evaluated using random assignment of 12 schools in Melbourne to an intervention condition and comparison against a further 12 matched schools. Follow-up was conducted with 2,000 students and their parents over three years from 2004. The intervention appeared promising, with parents and students positively evaluating the components delivered in the first year. ${ }^{46}$ After one year students exposed to the intervention reported educationally relevant improvements compared with the students in the control schools, including increased school rewards and attendance. ${ }^{55}$ Longer-term outcomes are in the process of being analysed and reported.

\section{Conclusions}

This review reveals a range of prevention-focused strategies that hold promise for addressing problems in low SES contexts that can undermine mental health. A common strategy has been that of improving early development and educational pathways. 
In a number of programs, long-term and multi-layered strategies have successfully improved a range of indicators underlying the intergenerational transmission of disadvantage. The findings point to the integrated nature of prevention and health promotion and suggest that intervention benefits in one area are likely to have reciprocal effects in reducing the health, social and mental health problems that tend to be prevalent in low SES communities.

\section{Acknowledgements}

Professor John Toumbourou is supported by a Senior Research Fellowship from the Victorian Health Promotion Foundation.

\section{References}

1. Hawkins JD, Herrenkohl TI, Farrington DP, Brewer D, Catalano RF, Harachi TW, et al. Predictors of youth violence. Juvenile Justice Bulletin. 2000;April.

2. Howell JC, Krisberg B, Hawkins JD, Wilson JJ. A Sourcebook: Serious, Violent, and Chronic Juvenile Offenders. Thousand Oaks (CA): Sage Publications; 1995.

3. Loeber R, Farrington DP. Serious and Violence Juvenile Offenders: Risk Factors and Successful Interventions. Thousand Oaks (CA): Sage Publications; 1998.

4. Loxley W, Toumbourou JW, Stockwell T. The Prevention of Substance Use, Risk and Harm in Australia: A Review of the Evidence. Canberra (AUST): Australian Government Department of Health and Ageing; 2004.

5. Scott D. Towards a Public Health Model of Child Protection in Australia. Communities, Children and Families Australia. 2006;1(1):9-16.

6. Stockwell T, Gruenewald P, Toumbourou JW, Loxley W. Recommendations for new directions in the prevention of risky substance use and related harms. In: Stockwell T, Gruenewald P, Toumbourou JW, Loxley W, editors. Preventing Harmful Substance Use: The Evidence Base for Policy and Practice. London (UK): Wiley; 2005. p. 337-350.

7. Toumbourou JW. Alcohol and drug use: Theoretically integrated interventions to prevent harm. In: Browning C, Thomas S, editors. Behavioural Change: An Evidence Based Handbook for Social and Public Health. Edinburgh (UK): Churchill Livingstone; 2005. p. 87-114.

8. Toumbourou JW, Stockwell T, Neighbors C, Marlatt GA, Sturge J, Rehm J. Interventions to reduce harm associated with adolescent substance use. Lancet. 2007;369(9570):1391-401.

9. Oxman AD. Checklists for review articles. Br Med J. 1994;309:648-51

10. Rehm J. Review papers in substance abuse research. Addiction. 1999;94(2):1736.

11. Boaz A, Pawson R. The perilous road from evidence to policy: 5 journeys compared. Journal of Social Policy. 2005;34:175-94.

12. Society for Prevention Research [homepage on the Internet]. Fairfax (VA): SPR; 2004 [cited 2007 Oct 26]. Standards of Evidence: Criteria for Efficacy, Effectiveness and Dissemination. Available from: http://www.preventionresearch.org/ StandardsofEvidencebook.pdf

13. Schoemaker DJ. Theories of Delinquency: An Examination of Explanations of Delinquent Behavior. 5th ed. New York (NY): Oxford University Press; 2005.

14. World Health Organization. World Report on Violence and Health. Geneva (CHE): WHO; 2002.

15. Raphael S, Winter-Ebmer R. Identifying the effect of unemployment on crime. Journal of Law and Economics. 2001;44:259-83.

16. Tittle CR, Meier RF. Specifying the SES/delinquency relationship by social characteristics of context. Journal of Research in Crime and Delinquency. $1991 ; 28: 430-55$

17. Sampson R, Lauritsen J. Violent victimization and offending: Individual-, situational-, and community-level risk factors. In: Reiss AJ, Roth JA, editors. Understanding and Preventing Violence. Vol 3. Social Influences. Washington (DC): National Academy Press; 1994. p. 1-114.

18. Farrington DP. Early predictors of adolescent aggression and adult violence. Violence and Vict. 1989;4:79-100.

19. Henry B, Caspi A, Moffitt TE, Silva PA. Temperamental and familial predictors of violent and nonviolent criminal convictions Age 3 to Age 18. Dev Psychol. 1996;32:614-23.

20. Weatherburn D, Lind B. What mediates the macro-level effects of economic and social stress on crime? Australian and New Zealand Journal of Criminology. 2006;39(3):384-97

21. Lipsey MW, Derzon JH. Predictors of violent or serious delinquency in adolescence and early adulthood. In: Loeber R, Farrington DP, editors. Serious and Violence Juvenile Offenders: Risk Factors and Successful Interventions. Thousand Oaks (CA): Sage Publications; 1998. p. 86-105.

22. Room R. Stigma, social inequality and alcohol and drug use. Drug Alcohol Rev. $2005 ; 24(2): 143-55$.

23. Graham H, Inskip HM, Francis B, Harman J. Pathways of disadvantage and smoking careers: evidence and policy implications. J Epidemiol Community Health. 2006;60(2):7-12

24. Williams J, Toumbourou JW, McDonald M, Jones S, Moore T. A sea change on the island continent: frameworks for risk assessment, prevention and intervention in child health in Australia. Children \& Society. 2005;19:91-104.

25. Claussen B. Alcohol disorders and re-employment in a 5-year follow-up of longterm unemployed. Addiction. 1999;94(1):133-8.

26. Dee TS. Alcohol abuse and economic conditions: evidence from repeated crosssections of individual-level data. Health Econ. 2001;10(3):257-70.

27. Johansson E, Bockerman P, Prattala R, Uutela A. Alcohol-related mortality, drinking behavior, and business cycles: are slumps really dry seasons? Eur J Health Econ. 2006;7(3):215-220.

28. LaMontagne AD, Shaw A, Ostry A, Louie AM, Keegel TG. Workplace Stress in Victoria - Developing a Systems Approach. Melbourne (AUST): Victorian Health Promotion Foundation; 2006.

29. Dohrenwend BP. The role of adversity and stress in psychopathology: some evidence and its implications for theory and research. I Health Soc Behav. 2000;41(1):1-19.

30. Wohlfarth T, van den Brink W. Social class and substance use disorders: the value of social class as distinct from socioeconomic status. Soc Sci Med. 1998;47(1):518.

31. Sachs J. The End of Poverty: How Can We Make it Happen in Our Lifetime. London (UK): Penguin; 2005.

32. Stanley F. Before the Bough Breaks - Children in Contemporary Australia. In: The Kenneth Myer Lecture; 2003 July 24. Canberra (AUST); Friends of the National Library of Australia; 2003.

33. Richardson S, Prior M. Childhood today. In: Richardson S, Prior M, editors. No Time to Lose. Melbourne (AUST): University of Melbourne Press; 2005.

34. Durlack J. Common risk and protective factors in successful prevention programs. Am J Orthopsychiatry. 1998;68:512-20.

35. United Nations Children's Fund (UNICEF). An Overview of Child well-being in Rich Countries. Florence (ITL): Innocenti Research Centre; 2007. Report Card No.: 7.

36. VicHealth. The Health Costs of Violence: Measuring the Burden of Disease Caused by Intimate Partner Violence. A Summary of Findings. Melbourne (AUST): Victorian Health Promotion Foundation; 2004.

37. Hester M, Pearson C, Harwin N, Abrahams H. Making an Impact: Children And Domestic Violence: A Reader. London (UK): Kingsley; 2007.

38. Humphreys $\mathrm{C}$. A health inequalities perspective on violence against women. Health and Social Care in the Community. 2006;15(2):120-7.

39. Walby S, Allen J. Domestic Violence, Sexual Assault and Stalking: Findings from the British Crime Survey. London (UK): Home Office Research, Development and Statistics Directorate; 2004. Home Office Research Study Report No.: 276

40. Toumbourou JW, Rowland B, Jefferies A, Butler H, Bond L. Preventing Drugrelated Harm through School Re-organisation and Behaviour Management. Melbourne (AUST): Druglnfo Clearinghouse, Australian Drug Foundation; 2004 Nov. p. 1-24. Prevention Clearinghouse Technical Report No.:12.

41. Olds DL, Henderson JCR, Kitzman H, Eckenrode J, Cole R, Tatelbaum RC. Prenatal and infancy home visitation by nurses: Recent findings. Future Child. 1999;9:4465 .

42. Catalano RF, Gainey RR, Fleming CB, Haggerty KP, Johnson NO. An experimental intervention with families of substance abusers: one-year follow-up of the focus on families project. Addiction. 1999;94:241-54.

43. Vinson T. Can locality-based strategies genuinely open up life opportunities for children in disadvantaged areas? Communities, Families and Children Australia. 2006;1(1):50-52.

44. Vinson T. Dropping Off the Edge: The Distribution of Disadvantage in Australia. Melbourne (AUST): Jesuit Social Services; 2007.

45. Homel R, Freiberg K, Lamb C, Leech M, Carr A, Hampshire A, et al. The Pathways to Prevention Project: The First Five Years, 1999-2004. Brisbane (AUST): Key Centre for Ethics, Law, Justice \& Governance, Griffith University; 2006.

46. Shortt AL, Fealy S, Toumbourou JW. The mental health Risk Assessment and Management Process (RAMP) for schools. Process evaluation. The Australian eJournal for the Advancement of Mental Health. 2006;5(3):1-12.

47. Hawkins JD, Smith BH, Hill K, Kosterman R, Catalano RF, Abbot RD. Understanding and preventing crime and violence: Findings from the Seattle Social Development Project. In: Thornberry, Krohn, editors. Taking Stock of Delinquency: An Overview of Findings from Contemporary Longitudinal Studies. New York (NY): Kluwer Academic; 2003. 
48. Hawkins JD, Kosterman R, Catalano RF, Hill K, Abbot RD. Promoting positive adult functioning through social development intervention in childhood: Longterm effects from the Seattle Social Development Project. Arch Pediatr Adolesc Med. 2005; 159(1):25-31.

49. Lonczak HS, Abbot RD, Hawkins JD, Kosterman R, Catalano RF. Effects of the Seattle Social Development Project on sexual behavior, pregnancy, birth, and sexually transmitted disease outcomes by age 21. Arch Pediatr Adolesc Med. 2002;156(5):438-47.

50. Hawkins JD, Catalano RF, Kosterman R, Abbot R, Hill K. Preventing adolescent health-risk behaviors by strengthening protection during childhood. Arch Paediatr Adolesc Med. 1999;153(3):226-34.

51. Hawkins JD, Guo J, Hill K, Battin-Pearson S, Abbot R. Long term effects of the Seattle Social Development intervention on school bonding trajectories. Applied Developmental Science. 2001;5(4):225-36.
52. Bond L, Thomas L, Coffey C, Glover S, Butler H, Carlin J. Long-term impact of the Gatehouse Project on cannabis use of 16-year-olds in Australia. J Sch Health. 2004;74(1):23-9.

53. Patton GC, Bond L, Carlin JB, Thomas L, Butler H, Glover S. Promoting social inclusion in schools: a group-randomized trial of effects on student health risk behavior and well-being. Am J Public Health. 2006;96(9):1582-7.

54. Toumbourou JW, Gregg ME. Impact of an empowerment-based parent education program on the reduction of youth suicide risk factors. J Adolesc Health. 2002;31:277-85.

55. Shortt AL, Hutchinson DM, Chapman R, Toumbourou JW. Family, school, peer and individual influences on early adolescent alcohol use: First year impact of the Resilient Families program. Drug Alcohol Rev. In press 2007.

\section{Authors}

J. W. Toumbourou, School of Psychology, Deakin University, Victoria; Centre for Adolescent Health, Murdoch Childrens Research Institute, Victoria; Department of Paediatrics, University of Melbourne, Victoria; and the Royal Children's Hospital, Victoria

S. A. Hemphill, Centre for Adolescent Health, Murdoch Childrens Research Institute, Victoria; Department of Paediatrics, University of Melbourne, Victoria; and the Royal Children's Hospital, Victoria

J. Tresidder, Youth Substance Abuse Service and Communities That Care Ltd, Victoria

C. Humphreys, School of Nursing and Social Work, University of Melbourne, Victoria

J. Edwards, Jesuit Social Services, Victoria

D. Murray, Youth Substance Abuse Service, Victoria

\section{Correspondence}

Professor John Toumbourou, School of Psychology, Deakin University, 1 Gheringhap Street, Geelong, Victoria 3217.

Tel: (03) 5227 8278; fax: (03) 5227 8455; e-mail: john.toumbourou@deakin.edu.au

\section{Author: ref 47, can we get initials on book editors}




\section{University Library}

\section{- M M N E R VA A gateway to Melbourne's research publications}

Minerva Access is the Institutional Repository of The University of Melbourne

Author/s:

Toumbourou, JW;Hemphill, SA;Tresidder, J;Humphreys, C;Edwards, J;Murray, D

Title:

Mental health promotion and socio-economic disadvantage: lessons from substance abuse, violence and crime prevention and child health.

Date:

2007-12

Citation:

Toumbourou, J. W., Hemphill, S. A., Tresidder, J., Humphreys, C., Edwards, J. \& Murray, D. (2007). Mental health promotion and socio-economic disadvantage: lessons from substance abuse, violence and crime prevention and child health.. Health Promot J Austr, 18 (3), pp.184-190. https://doi.org/10.1071/he07184.

Publication Status:

Published

Persistent Link:

http://hdl.handle.net/11343/33564 